\title{
Special issue dedication: David Ian Gibson
}

\author{
Aneta Kostadinova
}

(C) Springer Science+Business Media Dordrecht 2013

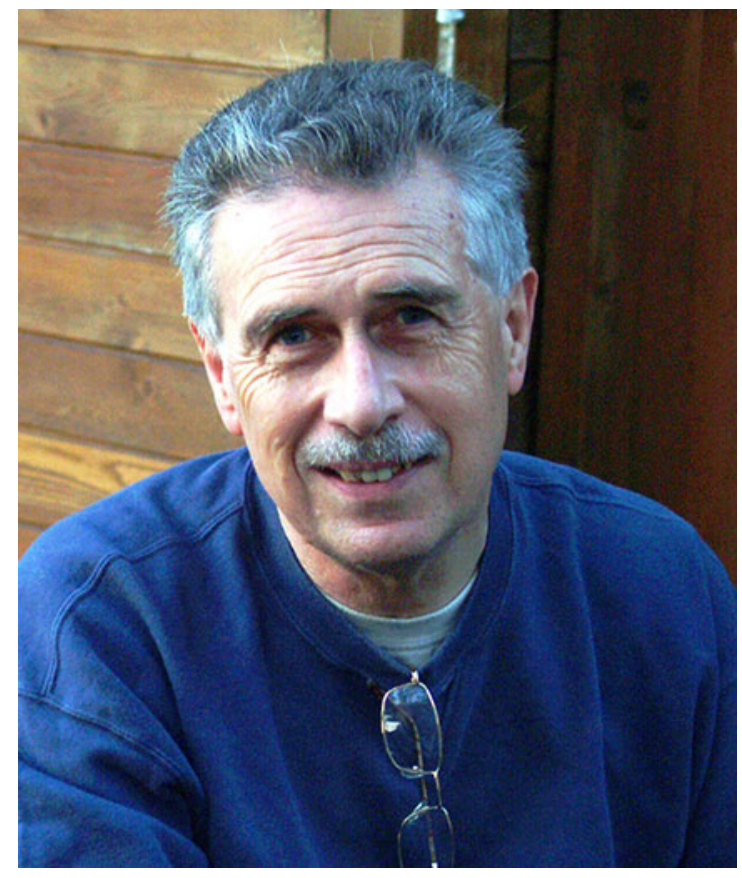

This issue of Systematic Parasitology is dedicated with deep admiration to Dr David Gibson on the occasion of his stepping down as editor-in-chief and in

\footnotetext{
A. Kostadinova ( $\square)$

Institute of Parasitology, Biology Centre, Academy of Sciences of the Czech Republic, České Budějovice, Czech Republic

e-mail: aneta.kostadinova@uv.es
}

recognition of his exceptional contributions to the development of the journal during the last 27 years.

David was born in Louth, Lincolnshire, England, in 1945, the son of a Scottish gas engineer and a Lincolnshire mother. He was educated at grammar schools at Louth and a little further north at Scunthorpe, to where his family moved when he was 11 . Following the acquisition of a First in Zoology at the University of Nottingham in 1967, he moved to Scotland and completed his $\mathrm{PhD}$ at the University of Aberdeen in 1971 under the supervision of Prof. Haffi Williams. His research on the helminth parasites of an estuarine flatfish lead to a life-time interest in marine parasitology and a life-time allergy to teleosts. Later, in 1989, David was awarded the DSc by the University of Nottingham.

In 1971 David joined the staff of the Department of Zoology of the then British Museum (Natural History), now the Natural History Museum, in London, as a research scientist. He has worked there ever since, as a senior research scientist (1973-1977), a principal researcher (1983-2005), head of the Parasitic Worms Division (1977-2005) and, following his formal retirement in 2005, as a scientific associate in the Parasites and Vectors Division of the Life Sciences Department.

David has more than 300 publications mainly on the taxonomy and systematics of a diverse range of parasite groups, but with a major focus on trematodes and nematodes. His first major publication appeared in 1976 and was soon followed by six other important 
monographs, co-authored by Rod Bray, on the NorthEast Atlantic digenean fauna, and a book on the trematodes of Canadian fishes in 1996. Although David has become 'the' authority on members of the digenean superfamily Hemiuroidea, his grasp of the functional morphology, taxonomy and systematics extends to a wide range of taxa within the Trematoda. This is demonstrated by his prolific output and his contributions (27 chapters) to and the editing of, with Arlene Jones and Rod Bray, the three-volume series Keys to the Trematoda. I am sure that the contributors to these volumes would agree that this outstanding series has greatly benefited from David's sharing of both his knowledge and great editorial skills.

His work has been well received internationally, as indicated by the honours, awards and offices that came his way. These include a Visiting Professorship at the University of Queensland, Australia, an Honorary Lectureship at the University of Stirling, Honorary Memberships of the Federation of Latin American Parasitologists and the Bulgarian Society for Parasitology, and Membership of External Advisory Panels for the Academies of Science of Finland and the Czech Republic. He examined DSc and PhD theses from Australia, Canada, Finland, India, Norway, Spain, Sweden and the UK.

David recognised the advantages of the development of electronic databases well before the appearance of the World Wide Web. Constant access to the Museum's Host-Parasite Catalogue, devised in manuscript form in 1922 by Dr H. A. Baylis, had a great impact on his work and that of his colleagues. By 1988 this catalogue contained records of host-parasite associations extracted from more than 70,000 references and had become very large and unwieldy, so David initiated the further collection of these data by the Parasitic Worms Division staff in electronic form. This involved fixed hours of data input on a daily basis, which he, and his colleagues, Rod Bray, Charles Hussey and Eileen Harris, strictly adhered to, an enormous effort, between 1988 and 2003. This resulted in the acquisition of more than a quarter of a million host-parasite-locality associations extracted from 28,000 references, all now available for on-line searches. This Host-Parasite Database is now a startup home page in many laboratories, especially those with large numbers of students. In his 'free' time, David has maintained the WWW Virtual Library: Parasitology, a website created in 1991, has acted as the editor for Animal Parasitic Helminths for the Fauna Europaea and the European Register of Marine Species, and has made significant recent contributions as editor (Digenea, Monogenea and Acanthocephala) for the World Register of Marine Species.

David is on the editorial boards of Acta Parasitologica, Folia Parasitologica, Helminthologia and ZooKeys and has previously served on the editorial boards of Parasitology, Annales de Parasitologie Humaine et Comparée, Ecological Parasitology and Zoologica Scripta. But he has devoted his main efforts to the development of Systematic Parasitology, which became his brainchild. At the time David succeeded the founder editor-in-chief, Dr Sheila M. Willmott, in 1986, the journal published four issues per year. Under his leadership the journal grew up rapidly, with six issues per year between 1987 and 1990, and settled on nine issues per year thereafter. The journal has rapidly established an international reputation for the publication of high-quality systematic and taxonomic research. It is difficult to imagine the amount of work associated with this growth, but he used to say that further expansion would kill the editor, which I thought was one of his fine jokes. Just a few numbers illustrate the enormous effort David dedicated to the high publication standard of our papers in Systematic Parasitology over the long years of meticulous editorial work: 77 volumes, 233 issues, 1,659 papers and 18,500 printed pages - all copy-edited. The latter number should be multiplied by four (i.e. submission, revision, editing, proof checking) to give a more realistic estimate of the astonishing amount of time and energy David invested on improving the quality of the accepted manuscripts and to maintaining the journal's standards and academic integrity. As a matter of fact, every manuscript submitted to Systematic Parasitology was subjected to three peer reviews, the last being David's, who scrutinised every detail, improving the style, text flow and integrity of the manuscript ... no error or ambiguity ever escaped his eagle eye!

While editing the journal, David has in fact been teaching at a distance at least three generations of young scientists, who keep fond recollections of his important comments, frequently associated with jokes to lighten the criticism. I feel fortunate for the chance to belong to the first generation profiting from his influence and generous mentorship, as are my students and their students, the second and the third generations. 
Six $\mathrm{PhD}$ students wrote their theses under David's direction, but the number of those whose theses have benefited substantially from the high demanding standards and scientific exchanges with David, the editor, is many times larger. This immense personal influence in fostering new talent and his intellectual generosity is reflected by a long list of patronyms (more than 30, and extended further in this issue) and has led to active, long-term collaborations with scientists from many countries, including Brazil, Bulgaria, China, Czech Republic, Finland, France, Italy, Malaysia, Poland, Russia, Spain and the Ukraine.
Mention should also be made of his long-suffering wife, Patricia, a Canadian virologist, without whose support he would have, so he tells me, achieved little.

I am delighted to express our thanks for David's profound impact on the development of Systematic Parasitology and to extend to him our very best wishes for continued activity in science and happiness. I am thrilled that David agreed to continue sharing his vast knowledge and experience by serving on the Editorial Board, because Systematic Parasitology is David Gibson! 